\title{
Presentación
}

\section{Pilar Sánchez-López}

Departamento de Psicología Evolutiva y de la Educación, Universidad de Almería

España

psanchez@ual.es 
Sumergirse como estudioso o como mero lector en el mundo de las necesidades específicas se asemeja en cierto modo a adentrarse en un territorio en el que casi todo parece dicho y, al tiempo, casi todo parece por decir; en el que la mayoría parece coincidir y, simultáneamente, coexisten diferentes discursos. Más allá de los juegos de palabras, lo cierto es que la educación especial tiene tras de sí una historia de siglos en la que, sin embargo, la conceptualización actual cuenta con unos pocos lustros de vida (Schalock, 1999). Complementariamente, sus raíces se hunden en la interdisciplinariedad y, sin ésta, su evolución es difícilmente comprensible, lo que implica que diferentes disciplinas presten aportaciones epistemológicas y, por ende, metodológicas divergentes - a veces opuestas - y que la temática en investigación esté dotada de una gran amplitud (Peñafiel y Torres, 2002).

Los trabajos que conforman este monográfico no son más que el nítido reflejo de la situación que acabamos de exponer. Conviven profesionales de distintas disciplinas (principalmente de la psicología, la educación y la sociología), atendiendo a diferentes categorías de excepcionalidad y necesidades (superdotación intelectual, déficit de atención, discapacidad motriz, dificultades de lenguaje, sordera y ceguera) y con diversos acercamientos teóricos y aplicados.

Si algo suscita acuerdo es la consideración de que el foco de interés debe quedar desplazado de la discapacidad a las necesidades concretas que ésta genera en un contexto determinado. Aunque existe una tendencia a extender el estudio de dichas necesidades (Ochaita y Espinosa, 2004), por motivos de tradición académica la escuela ha sido el ámbito preferente de estudio. Y, en este contexto, la inadecuación de la escuela tradicional para dar respuesta a la heterogeneidad y diversidad y la necesidad de cambio en la educación especial son también objeto de amplio consenso (Marchesi, 2001). El reto que supone la inclusión educativa tiene en distintos países diferentes grados de desarrollo. El trabajo de Mel Ainscow nos plantea los principios generales de la educación inclusiva desde el panorama inglés, donde ya existe una considerable trayectoria en su aplicación. Por otro lado, describiendo una situación diferente, el trabajo de Leyva constituye una reflexión acerca de cómo este nuevo modelo proveniente de las definiciones de la CIF se materializa en el contexto cubano.

Otra de las características de la visión actual es que, en la línea de una perspectiva ecológica (Schalock, 1999), la conceptualización de la discapacidad trasciende como etapa evolutiva y contexto de aprendizaje la edad escolar y se centra en la interacción entre la per- 
sona y su entorno: el trabajo de Tamara Polo y $\mathrm{M}^{\mathrm{a}}$ Dolores López Justicia nos traslada al ámbito universitario y las barreras físicas que en ese contexto han de afrontar los alumnos con discapacidad motriz, mientras que Alys Young y sus colaboradores se centran en el trabajo de orientación y asesoramiento a los padres de niños sordos y los profesionales que trabajarán con ellos, describiendo el trabajo que a este respecto se está llevando a cabo en la actualidad en el Reino Unido. Asimismo, desde una visión holística distintos trabajos empíricos intentan relacionar el ámbito de un área que genera necesidades específicas con otras áreas, como el trabajo de Ferrando y colaboradores, en el que se estudian las relaciones entre la inteligencia y la creatividad, o el de Juan Moreno y María Rosa Mateos, entre dislalia y personalidad y el de Luz Ramírez y su equipo que estudian distintos tipos de memoria y el TDAH.

Por último, parte importante del esfuerzo investigador que se da en este campo está encaminado a la elaboración de programas, instrumentos o materiales que ayuden a la detección, evaluación y diagnóstico e intervención de las personas con nee. En esta última línea se encuentra el artícullo de Vicente Félix, que expone una visión actualizada de la evaluación neuropsicológica y comportamental del TDA y el de Pilar Martín, más relacionado con las altas capacidades. Situado específicamente en la perspectiva interventora, Isidoro Candel describe de manera completa y exhaustiva la lógica subyacente a la elaboración de un programa de atención temprana, en tanto que Sáez realiza una aportación de gran interés de la mano de la estenografía como ayuda a los niños con problemas lectores. Es además evidente que las nuevas tecnologías se han convertido en una herramienta de inapreciable valor, como lo demuestran los trabajos de Carmen Hernández y África Borges, dedicado a la descripción de un interesante programa de aprendizaje autorregulado, y la original propuesta de Tomasa Sánchez y Francisco Salvador, que se proponen el reto de crear una red comunicativa entre distintos profesionales en el ámbito de la deficiencia visual.

No queremos terminar estas páginas sin agradecer profunda y sinceramente a todos los autores su participación, ya que la suma de todos sus esfuerzos ha sido decisiva para que este número vea la luz. 


\section{Referencias}

Marchesi, A. (2001). Del lenguaje de las deficiencias a las escuelas inclusivas. En A. Marchesi, C. Coll y J. Palacios (comps), Desarrollo psicológico y educación. 3. Trastornos del desarrollo y necesidades educativas especiales. Madrid: Alianza Editorial.

Ochaita, E. y Espinosa, M.A. (2004). Hacia una teoría de las necesidades infantiles y adolescentes. Madrid: McGraw-Hill.

Peñafiel, F. y Torres, J.A. (2002). Indicadores de calidad en la educación especial. Granada: Grupo Editorial Universitario.

Schalock, R.L. (1999). Hacia una nueva concepción de la discapacidad. En M.A. Verdugo y F. Jordán de Urríes (coords.), Hacia una nueva concepción de la discapacidad. Salamanca: Amarú. 